Article

\title{
Exploring VIIRS Continuity with MODIS in an Expedited Capability for Monitoring Drought-Related Vegetation Conditions
}

\author{
Trenton D. Benedict ${ }^{1, *}{ }^{\mathbb{D}}$, Jesslyn F. Brown ${ }^{2} \mathbb{D}$, Stephen P. Boyte ${ }^{2}$, Daniel M. Howard ${ }^{1}$, Brian A. Fuchs ${ }^{3}$, \\ Brian D. Wardlow ${ }^{4}\left(\mathbb{D}\right.$, Tsegaye Tadesse ${ }^{3}(\mathbb{D})$ and Kirk A. Evenson ${ }^{1}$ \\ 1 KBR, Contractor to U.S. Geological Survey Earth Resources Observation and Science (EROS) Center, \\ Sioux Falls, SD 57198, USA; dhoward@contractor.usgs.gov (D.M.H.); evenson@contractor.usgs.gov (K.A.E.) \\ 2 U.S. Geological Survey (USGS), Earth Resources Observation and Science (EROS) Center, 47914 252nd St., \\ Sioux Falls, SD 57198, USA; jfbrown@usgs.gov (J.F.B.); sboyte@usgs.gov (S.P.B.) \\ 3 National Drought Mitigation Center, University of Nebraska-Lincoln, 3310 Holdrege St., \\ Lincoln, NE 68583, USA; bfuchs2@unl.edu (B.A.F.); ttadesse2@unl.edu (T.T.) \\ 4 Center for Advanced Land Management Information Technologies, School of Natural Resources, \\ University of Nebraska-Lincoln, 3310 Holdrege St., Lincoln, NE 68583, USA; bwardlow2@unl.edu \\ * Correspondence: tbenedict@contractor.usgs.gov
}

\section{check for} updates

Citation: Benedict, T.D.; Brown, J.F.; Boyte, S.P.; Howard, D.M.;

Fuchs, B.A.; Wardlow, B.D.;

Tadesse, T.; Evenson, K.A. Exploring VIIRS Continuity with MODIS in an Expedited Capability for Monitoring Drought-Related Vegetation Conditions. Remote Sens. 2021, 13, 1210. http://doi.org/10.3390/ rs13061210

Academic Editor: Mikhail ZHIZHIN

Received: 11 February 2021

Accepted: 19 March 2021

Published: 23 March 2021

Publisher's Note: MDPI stays neutral with regard to jurisdictional claims in published maps and institutional affiliations.

Copyright: (C) 2021 by the authors Licensee MDPI, Basel, Switzerland. This article is an open access article distributed under the terms and conditions of the Creative Commons Attribution (CC BY) license (https:// creativecommons.org/licenses/by/ $4.0 /)$.
Abstract: Vegetation has been effectively monitored using remote sensing time-series vegetation index (VI) data for several decades. Drought monitoring has been a common application with algorithms tuned to capturing anomalous temporal and spatial vegetation patterns. Drought stress models, such as the Vegetation Drought Response Index (VegDRI), often use VIs like the Normalized Difference Vegetation Index (NDVI). The EROS expedited Moderate Resolution Imaging Spectroradiometer (eMODIS)-based, 7-day NDVI composites are integral to the VegDRI. As MODIS satellite platforms (Terra and Aqua) approach mission end, the Visible Infrared Imaging Radiometer Suite (VIIRS) presents an alternate NDVI source, with daily collection, similar band passes, and moderate spatial resolution. This study provides a statistical comparison between EROS expedited VIIRS (eVIIRS) 375-m and eMODIS 250-m and tests the suitability of replacing MODIS NDVI with VIIRS NDVI for drought monitoring and vegetation anomaly detection. For continuity with MODIS NDVI, we calculated a geometric mean regression adjustment algorithm using 375-m resolution for an eMODIS-like NDVI $\left.(\mathrm{eVIIRS})^{\prime}\right)$ eVIIRS $=0.9887 \times \mathrm{eVIIRS}-0.0398$. The resulting statistical comparisons (eVIIRS' vs. eMODIS NDVI) showed correlations consistently greater than 0.84 throughout the three years studied. The eVIIRS' VegDRI results characterized similar drought patterns and hotspots to the eMODIS-based VegDRI, with near zero bias.

Keywords: visible infrared imaging radiometer suite; eVIIRS; moderate resolution imaging spectroradiometer; eMODIS; normalized difference vegetation index; vegetation drought response index; VegDRI; remote sensing satellites; geometric mean regression

\section{Introduction}

Drought conditions can range from moderate to exceptional and with varying duration, requiring continuous, operational monitoring. The longer a drought lasts and the more exceptional its effects on vegetation and water resources, the more a drought can alter services for humans and modify natural systems. Drought effects include the degradation of habitat for wildlife and water quality, reduced access to water resources [1], and increases in disturbances like fire events [2]. Drought can also affect agriculture, water supplies, energy production, and many other aspects of society [3]. Drought monitoring is therefore critical for researchers, land managers, and decision makers to identify regions where drought mitigation and planning are necessary. Satellite-based remote sensing has 
proven useful for drought and vegetation monitoring because of its synoptic coverage, hightemporal repeat cycle, and continuous, moderate-resolution observations of satellite-based sensors [3].

In the United States, the U.S. Drought Monitor (USDM) (http:/ / droughtmonitor. unl.edu/, accessed on 11 February 2021) is the key, national-level monitoring tool that integrates various types of in situ, remotely sensed and modeled information along with drought expert input to characterize and map drought conditions on a weekly basis [4]. Instead of relying on a single drought indicator or index, the USDM authors use several dozen inputs in which the attributes of all are considered, utilizing the strengths that each provides in a hybrid approach. This "convergence of evidence" approach allows the USDM authors to utilize many resources that include drought indices, surface data, hydrology data, soil moisture data, modeled data, and remotely sensed data as well as input from local drought experts. The use of remote sensing to support the USDM has greatly increased over the past decade with many new tools created to characterize various vegetation and hydrologic conditions [5]. Given the weekly, operational mandate of the USDM to map national-level drought conditions, applicable remote sensing tools must also be operational and have a long-term data continuity plan to produce near real-time products into the future. From a remote sensing perspective, long-term data consistency and continuity is a challenge as satellite-based sensors such as the Moderate Resolution Imaging Spectroradiometer (MODIS) degrade and are eventually taken out of operation at the end of their life span and replaced by new sensors such as Visible Infrared Imaging Radiometer Suite (VIIRS) that may have different sensor characteristics.

The Vegetation Drought Response Index (VegDRI) is an operational drought monitoring tool covering the continental United States since 2009. VegDRI is often used by the USDM and other drought applications developed to detect near real-time drought-related vegetation stress using satellite-based Normalized Difference Vegetation Index (NDVI) and other input data (e.g., climate data, soils, and land cover/land use). The current operational VegDRI production relies on weekly, EROS expedited Moderate Resolution Imaging Spectroradiometer (eMODIS) NDVI data produced at the U.S. Geological Survey (USGS) Earth Resources Observation and Science (EROS) Center since 2008. The USGS EROS Center developed eMODIS NDVI to offer the user community an "enhanced," "expedited," and "expandable" MODIS product, based on both Terra and Aqua data [6,7] (https://doi.org/10.5066/F7H41PNT, accessed on 11 February 2021). The Land Atmosphere Near real-time Capability for Earth Observing System (EOS) (LANCE) provides daily MODIS products that are ingested into expedited MODIS NDVI composites in order to meet the 24-h latency production of VegDRI on a weekly schedule. The eMODIS data have not only been used in VegDRI, but also to study a broad range of other land process topics including ecosystem performance in the Yukon River Basin of Alaska [8], die-off of cheatgrass in the northern Great Basin [9], and forest and rangeland dynamics in the Greater Platte and the Upper Colorado River Basins [10].

MODIS platforms, Terra (morning data acquisition) and Aqua (afternoon acquisition), were launched in 2000 and 2002, respectively, and have been vigorously used for almost two decades in many studies, including monitoring vegetation anomalies such as drought [6,11-13], fire danger monitoring [14], estimating crop yields [15,16], and mapping of invasive species [9]. MODIS has also been frequently used to produce vegetation indices such as the enhanced vegetation index, NDVI, and the drought severity index [6,11-13]. As the MODIS sensors approach the end of their life span, the data have started to show sensor degradation [17], impacting the quality of eMODIS. Wang et al. [17] found that Collection 5 Terra and Aqua MODIS NDVI values began to show negative bias in NDVI trends after analyzing reflectance data from 2002 to 2010. There is strong indication that the aging C6 Aqua MODIS sensor's NDVI will develop a similar trend in the future until data reprocessing fixes the negative bias [17]. Before negative NDVI trends affect C6 Aqua MODIS without reprocessing, vegetation anomaly models such as VegDRI and other 
eMODIS applications are looking to transition from eMODIS or the standard MODIS data products to data from VIIRS, which provides time-series vegetation index (VI) data.

The VIIRS sensor, on board the joint National Aeronautics and Space Administration (NASA) and National Oceanic and Atmospheric Administration (NOAA) Suomi National Polar-orbiting Partnership (Suomi-NPP) satellite, was launched in October 2011, with the potential to interchange with standard MODIS surface reflectance data. VIIRS consists of 22 spectral bands: 16 are 750-m moderate resolution bands (M-bands), five are 375-m imagery resolution bands (I-bands), and one consists of night and day data $[18,19]$. The Level 3 products, often used for comparison studies, are the outcome of the best selected Level 2 pixels based on observation coverage, low sensor angle, no cloud or cloud shadow, and aerosol loading, and spatially and temporally aggregated to 1-km (more precisely $963-\mathrm{m}$ ) and 500-m (more precisely 463-m) for the M- and I-bands, respectively [19,20]. The VIIRS sensor was designed as the follow-on Earth observation instrument to MODIS [20,21], and is already being utilized by several monitoring applications [22,23].

VegDRI uses eMODIS rolling 7-day NDVI composites ending with each Sunday processing period for a Monday delivery. To match this schedule, it would need to ingest a 7day temporal composite from VIIRS rather than NASA's standard 8-day VIIRS composites. To rectify this temporal mismatch, EROS has presented an expedited version of VIIRS referred to as eVIIRS. Daily VIIRS products are also acquired from the LANCE system to fulfil a 24-h latency production for VegDRI as required for USDM analysis. The eVIIRS dataset includes rolling 7-day expedited NDVI composites at 375-m and 1-km spatial resolutions (https:/ / doi.org/10.5066/P9Q3B2A7, accessed on 11 February 2021).

NDVI has been analyzed between multiple sensors to determine if any bias exists [20,24-26]. One recent study [20] compared 8-day composites (500-m resolution) and daily Climate Model Grid ( $0.05^{\circ}$ resolution) from VIIRS and MODIS surface reflectance data from 2012 to 2016, finding that VIIRS and MODIS NDVI can be interchangeable with low error (root mean square error (RMSE) less than 0.02 to 0.05 ). The low uncertainties and strong correlations were due to an applied spectral adjustment to VIIRS Red (I1) and Near-Infrared (NIR) (I2) bands before producing NDVI values, which is known as the distributed method. Skakun et al. [20] noted that the spectral adjustment reduced the potential bias in their comparisons. An earlier study compared VIIRS, MODIS, and Advanced Very High Resolution Radiometer (AVHRR) datasets and showed strong compatibility in the NIR band passes between VIIRS and MODIS [25]. Because NDVI calculations are strongly influenced by the NIR band, Miura et al. [25] also found that VIIRS and MODIS NDVI values were highly compatible with each other. The compatibility results of Miura et al. [25] illustrate that a transformation equation can be developed from MODIS and VIIRS NDVI values.

Kogan et al. [23] analyzed VIIRS NDVI-based drought detection capabilities compared with AVHRR, using the vegetation health index, demonstrated in applications since 2005. These authors found that the use of VIIRS data improved drought detection in its area, intensity, duration, and drought impacts compared to previous sensor products (i.e., AVHRR and MODIS) [23].

Building on the studies comparing NDVI with VIIRS and MODIS, we compare 7-day composite surface reflectance NDVI-based vegetation anomaly products (VegDRI) from both eVIIRS and eMODIS to determine their compatibility. This comparison is needed because eMODIS is the source data for current operational drought monitoring in VegDRI, which the USGS plans to continue producing in the future. This study has two main objectives: (1) develop an algorithm to convert eVIIRS NDVI to eMODIS-like NDVI (referring to the transformed eVIIRS NDVI as eVIIRS') and compare the eMODIS and eVIIRS NDVI datasets; and (2) test eVIIRS' NDVI and subsequent derivative vegetation anomaly products for use in the VegDRI drought monitoring production systems and investigate the propagation and influence of any differences that may exist between the NDVI datasets in VegDRI. We hypothesize that eVIIRS NDVI-based vegetation anomaly products are closely comparable to their eMODIS-based counterparts, provided that the NDVI data are 
corrected for bias. This work will ameliorate future anticipated restrictions on MODIS due to degradation or end of mission data stoppage. A broadly usable and robust national-level NDVI transformation is based on previous years' eMODIS and eVIIRS comparisons preferentially selected to have low RMSE. This work expands on previous studies by introducing real world applications to near real-time data, along with transitioning from native 250-m eMODIS to 375-m eVIIRS NDVI, and applying a three-year transformation regression on an independent year of data.

\section{Materials and Methods}

\subsection{Study Area}

The study area was the conterminous United States (CONUS), the same extent as that of VegDRI products. The area where NDVI pixel values were flagged as good quality, based on the associated eVIIRS and eMODIS composite quality products, were extracted to calculate our transformation equation. The overlapping eVIIRS and eMODIS good quality pixels were utilized to eliminate pixels which included NDVI values that had poor quality in one product and good quality in the other. For example, if the eVIIRS 375-m quality product labeled a pixel as "good" and the eMODIS 250-m quality product labeled that same area as "poor," then those pixels were thrown out. Poor quality pixels are defined as either water, clouds, cloud shadows, snow, bad band quality (based on band quality information), or fill values according to the eVIIRS or eMODIS quality band layers. These masks were used to define locations within CONUS that had good quality pixels and had identical conditions for producing an NDVI relation between eVIIRS and eMODIS. This procedure was performed on every set of eVIIRS and eMODIS weekly composites in the time series to produce unique good quality pixel boundaries. Within each good quality pixel boundary, 100,000 points were randomly distributed and used to extract the overlapping pixels of the different resolutions.

\subsection{Data}

This study involves eVIIRS 7-day rolling NDVI composites. To create these composites, daily 375-m VIIRS surface reflectance data (products VNP09 and NPP_IMFTS_L1) were downloaded from LANCE and a weekly 7-day download from Level-1 and Atmosphere Archive and Distribution System (LAADS). The eVIIRS data are temporally composited using the enhanced maximum value composite at spatial resolutions of $375-\mathrm{m}$ and $1-\mathrm{km}$ (https:/ / doi.org/10.5066/P9Q3B2A7, accessed on 11 February 2021). The enhanced maximum value composite algorithm fills in the pixel value with the highest NDVI within the 7-day composite for the current pixel and takes into account band quality, cloud mask, negative surface reflectance, and view angle for eVIIRS processing [7]. The NDVI calculations for the composites used the imagery bands I1 $0.600-0.680 \mu \mathrm{m}$ (red) and I2 $0.846-0.885 \mu \mathrm{m}$ (NIR) $[19,23]$. An NDVI adjustment calculation was derived from historical 375-m eVIIRS data for 2016-2018. To test the performance of the geometric mean regression (GMR) adjustment, eVIIRS 375-m and 1-km NDVI composites from 2020 were used. The 2020 eVIIRS includes recent composites that are created in near real-time, which are created within a day of the 7-day composite, unlike the gathering of historical data which creates 7-day composites from historical daily NDVI products.

The other product for comparison was Collection 6 (C6) Aqua eMODIS NDVI developed by the USGS EROS Center, downloaded from EarthExplorer (https: / / doi.org/10.506 6/F7H41PNT, accessed on 11 February 2021). The eMODIS NDVI product was developed from the C6 Aqua MODIS daily surface reflectance (MYD09GQ 250-m) and MODIS C6 Daily MYD09GA products (L2G Global 1-km and 500-m). Daily surface reflectance is also downloaded from LANCE and LAADS; further developmental details on eMODIS are provided here: https: / / doi.org/10.5066/F7H41PNT, accessed on 11 February 2021. The parameters and specific details of eMODIS are comparable to MODIS C6 products. The eMODIS NDVI data at 250-m and 1-km resolution were developed from MODIS bands B1 $0.62-0.67 \mu \mathrm{m}$ (red) and B2 $0.841-0.876 \mu \mathrm{m}$ (NIR) for evaluating compatibility with VIIRS 
I1 and I2, respectively [7,19]. The eMODIS composite period is a rolling 7-day composite with a temporal coverage for this study from 2016-2018. The eMODIS NDVI composites used for comparison in our study consist of 250-m NDVI composites from the historical data and a 1-km composite from 2020 eMODIS. The expedited composites are important for testing because these NDVI composites are one of the components that fuel the VegDRI model output.

For drought anomaly testing, separate VegDRI data products were generated for four 7-day composites during the recent 2020 western U.S. drought using both the eVIIRS and eMODIS NDVI data as input, respectively. VegDRI data products were generated over the CONUS for composite Weeks 29-32 starting with the first 7-day composite period on 20 July 2020, and ending with the fourth and final composite on 09 August 2020. VegDRI products were created in parallel with eMODIS NDVI and the transformed eVIIRS (eVIIRS') NDVI for each of these composite periods.

\subsection{Methods}

NDVI data from eVIIRS and eMODIS (native spatial resolutions of 375-m and 250-m, respectively) were used in this study to identify a transformation algorithm. Figure 1 shows both datasets at their native resolution, which was more effective at screening out noise (e.g., cloud cover, cloud shadows, filler values, etc.) in the data than using the spatially-aggregated 1-km resolution NDVI that is used in VegDRI. Coarser resolution $(1-\mathrm{km})$ may interfere with our transformation by including other land cover classes, as compared to higher resolution (250-m or 375-m) pixels which are more likely to have similar land cover. We noticed a visually cleaner NDVI composite image with less noise artifacts in eVIIRS data than eMODIS data as shown in Figure 1 during a visual quality assurance exercise. To transform eVIIRS NDVI to an eMODIS-like (hereafter the transformed eVIIRS NDVI is referred to as eVIIRS') NDVI, we used the lumped method (using the NDVI data to calculate a transformation equation for the new NDVI) for a simplistic approach to accommodate eMODIS users. This approach involved transforming NDVI-to-NDVI instead of translating using the distributed method (transforming the red and NIR bands to calculate a transformed NDVI) Band-to-NDVI [27]. The eVIIRS NDVI was transformed using the GMR developed from our eVIIRS and eMODIS correlation statistics described in the results section $[28,29]$. The GMR transformation was selected because the inverse can be used to transform historical eMODIS NDVI to eVIIRS-like NDVI values if this transformation is needed to create similar historical continuity in NDVI values, but for our study we adhere to transforming eVIIRS NDVI to eVIIRS' [30,31].

Four composites of eVIIRS NDVI data over the CONUS for mid-summer were transformed and analyzed using the new GMR developed from 2016-2018 data. Figure 2 illustrates the process for transforming eVIIRS NDVI by applying the GMR. The process evaluated if previous years could predict, or transform, a subsequent year and how robust the function was to transform eVIIRS NDVI to eMODIS-like NDVI values. We used 20162018 NDVI data to test this robustness with the current year's (2020) data, which gave us a year and a half gap from the last data received from MODIS (2018 in this situation) to the current processing year (2020). 


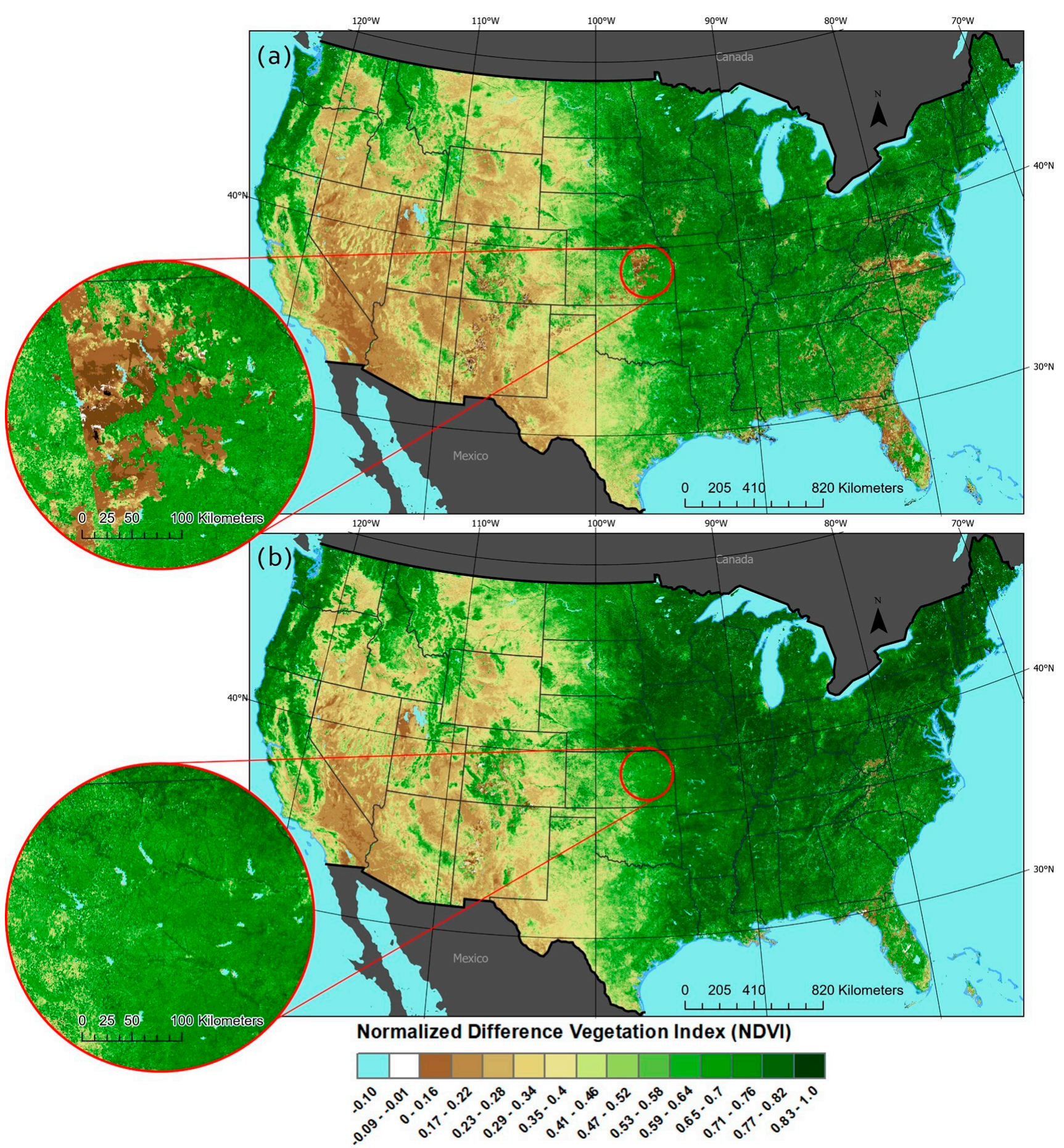

Figure 1. Expedited Moderate Resolution Imaging Spectroradiometer (eMODIS) 250-m Normalized Difference Vegetation Index (NDVI) (a) and expedited Visible Infrared Imaging Radiometer Suite (eVIIRS) 375-m NDVI (b) for composite (Julian day of year 215-221), 2016. Highlighted location in eastern Kansas shows an example of how eVIIRS composites have less noise artifacts than eMODIS composites. 


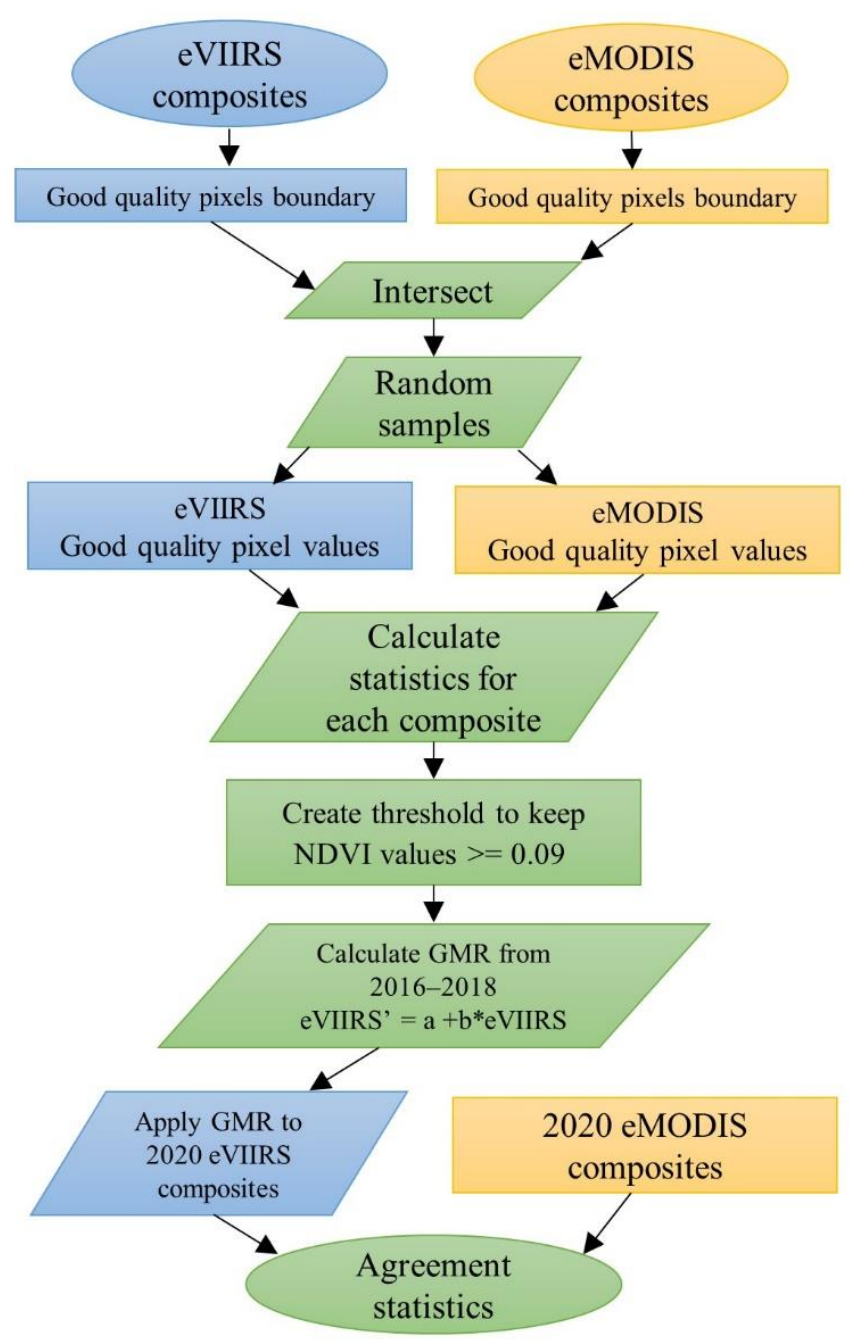

Figure 2. Methods for the geometric mean regression (GMR) transformation from expedited Visible Infrared Imaging Radiometer Suite (eVIIRS) to transformed eVIIRS (eVIIRS').

Our NDVI samples were derived by randomly selecting 100,000 pixels per NDVI composite. First, we applied our study area mask to gather sample data so that only good quality pixels would be used to derive the translation. We extracted NDVI pixels based on the pixel quality information for both eVIIRS and eMODIS. To ensure pixels that were randomly selected for comparison were "good quality" pixels in both eVIIRS and eMODIS, we intersected the boundaries of each composite. Furthermore, the translation formula was restrained within the "good quality" boundary by pixels that were acquired on the same Julian day-of-year (DOY) based on the acquisition band for each composite.

The standard NDVI formula was used for VIIRS bands I1 and I2:

$$
\mathrm{NDVI}=\left(\rho_{\text {NIR }}-\rho_{\text {red }}\right) /\left(\rho_{\text {NIR }}+\rho_{\text {red }}\right),
$$

where $\rho_{\text {NIR }}$ represents the NIR band (VIIRS I2) and $\rho_{\text {red }}$ represents the red band (VIIRS I1) [32].

The eVIIRS and eMODIS data are composited for an entire year (52, 7-day composites) and were used for statistical comparison. We compared eVIIRS NDVI and eMODIS NDVI data from individual years (one year at a time) and three-year composites (stacked across 2016, 2017, and 2018). We investigated many different approaches to develop the GMR transformation based on varying criteria for the NDVI values used and found that using NDVI values from all composites greater than 0.09 created the best results. We chose NDVI values of greater than 0.09 because lower values were associated with bare ground and 
dormant vegetation [8,33]. The 0.09 NDVI threshold eliminated noise that biased the GMR slope from a 1-to-1 relation, compared to slope closer to 1 when applying the threshold. The total number of pixels evaluated changed, depending on if we included all NDVI values or only NDVI values greater than 0.09 per composite.

We replaced four weekly composites of eMODIS NDVI 2020 data with four weekly composites from eVIIRS' NDVI 2020 data that were coincident in time in VegDRI calculations to see near real-time results. Then we extracted a new set of random pixel values using the previously described method for each of the four NDVI composites to compare the eVIIRS' and eMODIS VegDRI results over the CONUS to determine how well the drought patterns correlated when these two different NDVI datasets were used in the index calculation.

A statistical approach used to determine correlation agreement was the Agreement Coefficient (AC) [30]. The AC value measures the total agreement between two images, which includes data distances between the actual observations, 1-to-1 line, and regression line [30]. The AC was used to compare eVIIRS and eMODIS because it was found to be more suitable than other approaches based on linear regression as it compares different satellite images based on their slope relative to a 1-to-1 line [30]. To identify the linear regression between eVIIRS and eMODIS NDVI, we use the GMR because it has a more symmetrical property and can be interchanged with the $x$ and $y$ variables $[22,24,25,30,31]$. The AC was also used to relate to the coefficient of determination $\left(R^{2}\right)$ based on the Ordinary Least Squares regression [31]. AC values showed the spread of points relative to the 1-to-1 line and $R^{2}$ measured the points around the regression line, both considered to have perfect agreement/correlation when the calculation equals 1 .

To determine accuracy and error, we used mean bias error (MBE) and RMSE (Equations (2) and (3):

$$
\begin{aligned}
\mathrm{MBE} & =\frac{1}{N} \sum_{i=1}^{N}\left(y_{i}-x_{i}\right), \\
\mathrm{RMSE} & =\sqrt{\frac{1}{N} \sum_{i=1}^{N}\left(y_{i}-x_{i}\right)^{2}},
\end{aligned}
$$

where $N$ is the total number of sample points, $y_{i}$ is eVIIRS NDVI value, and $x_{i}$ is eMODIS NDVI value. MBE and RMSE are considered perfect when equal to zero. Relative root mean square error (RRMSE) is calculated by dividing the RMSE by the mean value of measured data (eVIIRS NDVI) and multiplied by 100 [34,35]. The RRMSE was used to determine whether the transformed eVIIRS NDVI values were a good fit compared to eMODIS NDVI. For eVIIRS to be an excellent fit, an RRMSE value of less than $10 \%$ is required, for a good fit the RRMSE value will be between $10 \%$ and $20 \%$, a fair fit is between $20 \%$ to $30 \%$, and a poor fit has values that are greater than $30 \%$ [34,35].

\section{Results}

\subsection{NDVI Transformation}

When transforming eVIIRS NDVI to eVIIRS' NDVI, we first evaluated the correlation between eVIIRS and eMODIS at their native resolutions of 375-m and 250-m, respectively. This approach builds upon Skakun et al. [20] who compared reflectance bands (red and NIR) and NDVI products at their 8-day composites and Climate Model Grid native resolutions without pixel aggregation. With three years of historical eVIIRS data, we were able to develop a GMR transformation algorithm (Equation (4) to apply to the three individual years and then to four eVIIRS NDVI 2020 composites.

$$
\text { eVIIRS' }^{\prime} 0.9887 \times \text { eVIIRS }-0.0398,
$$

where eVIIRS variable are eVIIRS NDVI composites and eVIIRS' are the eMODIS-like NDVI results. In Table 1, the correlation statistics represent the comparison between native resolution eVIIRS 375-m and eMODIS 250-m for each year consisting of 52 7-day NDVI composites. 
The native eVIIRS and eMODIS are highly correlated, with $R^{2}$ values above 0.84 in each year (2016-2018). The data also have strong ACs with all NDVI comparisons above 0.84, which represents good image-to-image comparison [30] compared to the 1-to-1 line. There is a slight positive bias (MBE between 0.043 and 0.051) in the eVIIRS NDVI relative to eMODIS, a finding also reported by Skakun et al. [20].

Once the GMR transformation was applied to 2020 eVIIRS NDVI to create 2020 eVIIRS' NDVI, bias decreased by more than $62 \%$, and RMSE decreased by more than $17 \%$. In Figure 3d, a slight bias toward 2020 eVIIRS' NDVI is shown with the 1-to-1 line (dashed) and GMR (solid), based on the four expedited composites we tested. Although the correlation statistics remained similar, the AC increased, resulting in less bias from the 1-to-1 relation between eVIIRS' and eMODIS NDVI.

(a)

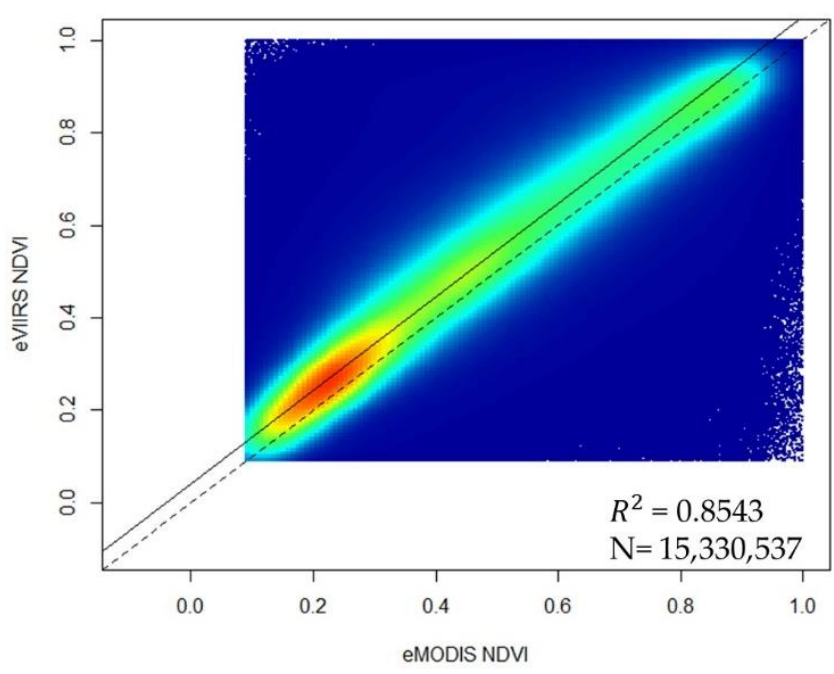

(b)

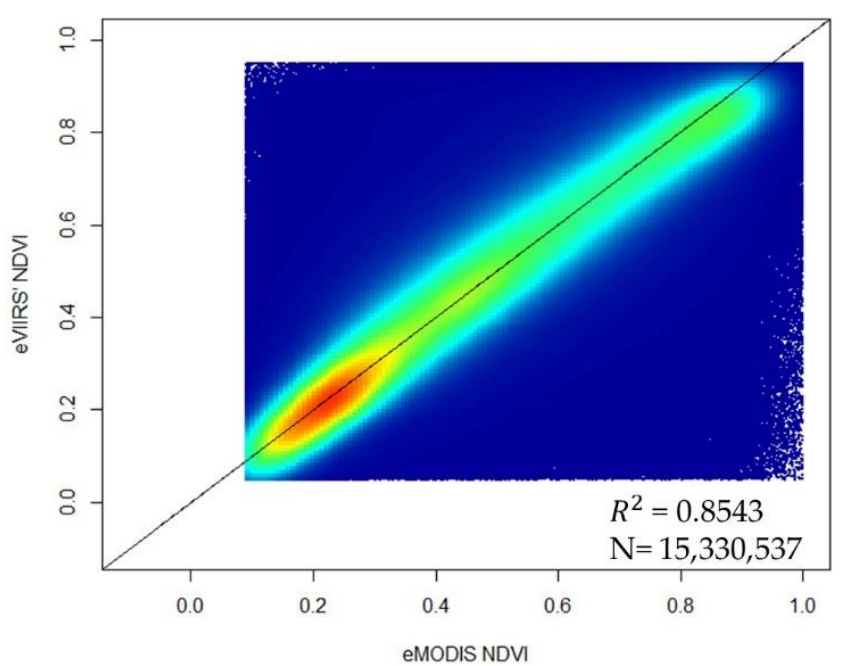

(c)

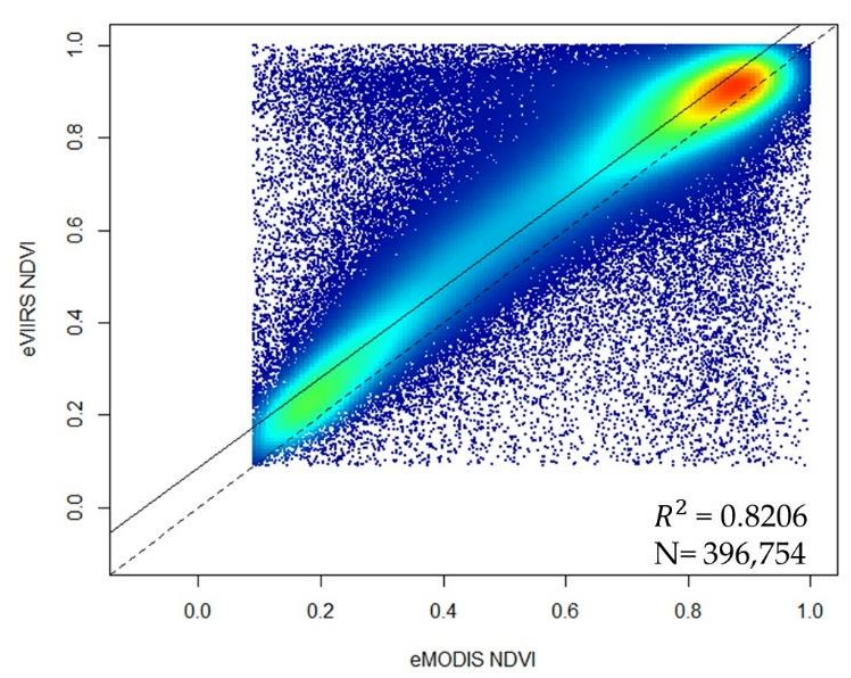

(d)

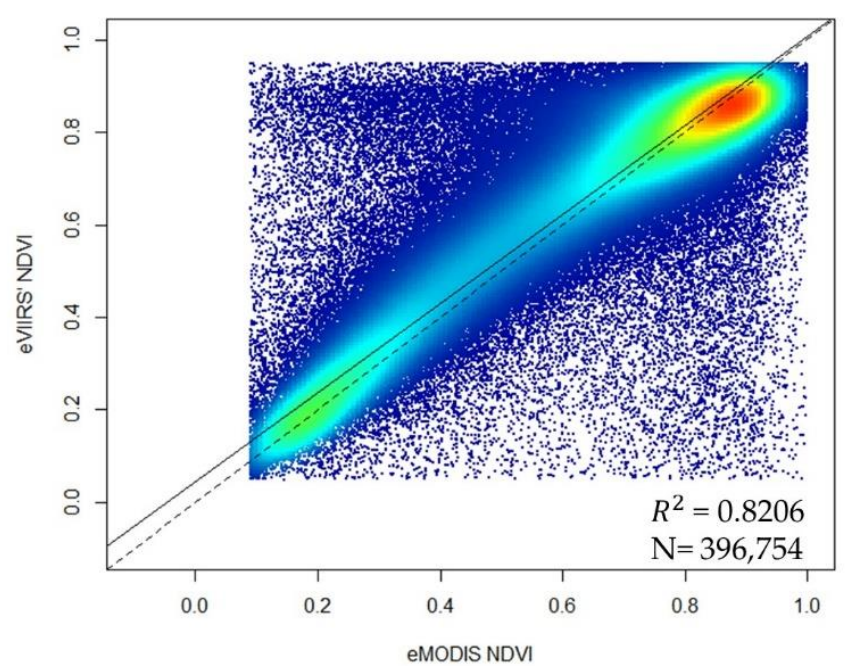

Figure 3. Expedited Visible Infrared Imaging Radiometer Suite (eVIIRS) and expedited Moderate Resolution Imaging Spectroradiometer (eMODIS) Normalized Difference Vegetation Index (NDVI) comparisons with all composites, (a) 20162018 eMODIS NDVI vs. eVIIRS NDVI, (b) 2016-2018 eMODIS NDVI vs. eVIIRS' NDVI, (c) 2020 eMODIS NDVI vs. eVIIRS NDVI, and (d) 2020 eMODIS NDVI vs. eVIIRS' NDVI. The eVIIRS NDVI composites are 375-m and eMODIS NDVI composites are 250-m. The visual aspects of eVIIRS' and eMODIS are shown in Figure 4, where the corresponding composite week's comparisons are illustrated in Figure 4c,d. Point density increases from low (blue) to moderate (green) to high (red), the geometric mean regression (solid line) and the 1-to-1 line (dashed line). 
Table 1. Expedited Visible Infrared Imaging Radiometer Suite (eVIIRS) Normalized Difference Vegetation Index (NDVI) comparison to expedited Moderate Resolution Imaging Spectroradiometer (eMODIS) NDVI. In the 2020 column, the results include the four 375-m and 1-km 7-day NDVI composites, starting with composites Julian day of year 196-202 through 217-223. The plain text values represent eVIIRS compared to eMODIS and the bold text values represent transformed eVIIRS (eVIIRS') compared to eMODIS. Pearson's R significance test resulted in $p$-values $<2.2 \times 10^{-16}$ for all of the years processed.

\begin{tabular}{|c|c|c|c|c|c|c|}
\hline $\begin{array}{l}\text { eVIIRS vs. eMODIS } \\
\text { eVIIRS' vs. eMODIS }\end{array}$ & $\begin{array}{c}2016 \\
(375-\mathrm{m})\end{array}$ & $\begin{array}{c}2017 \\
(375-\mathrm{m})\end{array}$ & $\begin{array}{c}2018 \\
(375-\mathrm{m})\end{array}$ & $\begin{array}{c}2020 \\
(375-\mathrm{m})\end{array}$ & $\begin{array}{c}2020 \\
(1-\mathrm{km})\end{array}$ & $\begin{array}{c}2016-2018 \\
(375-\mathrm{m})\end{array}$ \\
\hline \multirow{2}{*}{ Pearson's R } & 0.9390 & 0.9176 & 0.9171 & 0.9059 & 0.9162 & 0.9243 \\
\hline & 0.9391 & 0.9176 & 0.9171 & 0.9059 & 0.9162 & 0.9243 \\
\hline \multirow{2}{*}{$R^{2}$} & 0.8818 & 0.8419 & 0.8411 & 0.8206 & 0.8394 & 0.8543 \\
\hline & 0.8818 & 0.8419 & 0.8411 & 0.8206 & 0.8394 & 0.8543 \\
\hline \multirow{2}{*}{$\mathrm{AC}$} & 0.8766 & 0.8471 & 0.8467 & 0.8255 & 0.8337 & 0.8570 \\
\hline & 0.8774 & 0.8296 & 0.8305 & 0.8236 & 0.8459 & 0.8415 \\
\hline \multirow{2}{*}{ MBE/Accuracy } & 0.0506 & 0.0434 & 0.0434 & 0.0701 & 0.0786 & 0.0454 \\
\hline & 0.0051 & -0.0020 & -0.0035 & 0.0228 & 0.0312 & 0.0000 \\
\hline \multirow{2}{*}{ RMSE/Uncertainty } & 0.0937 & 0.1028 & 0.1029 & 0.1318 & 0.1293 & 0.1000 \\
\hline & 0.0786 & 0.0926 & 0.0934 & 0.1107 & 0.1067 & 0.0886 \\
\hline \multirow{2}{*}{ RRMSE (\%) } & 20.3513 & 22.3428 & 22.8878 & 21.8264 & 21.7363 & 21.8790 \\
\hline & 17.0683 & 20.1326 & 20.7917 & 18.7904 & 17.9322 & 19.3747 \\
\hline
\end{tabular}

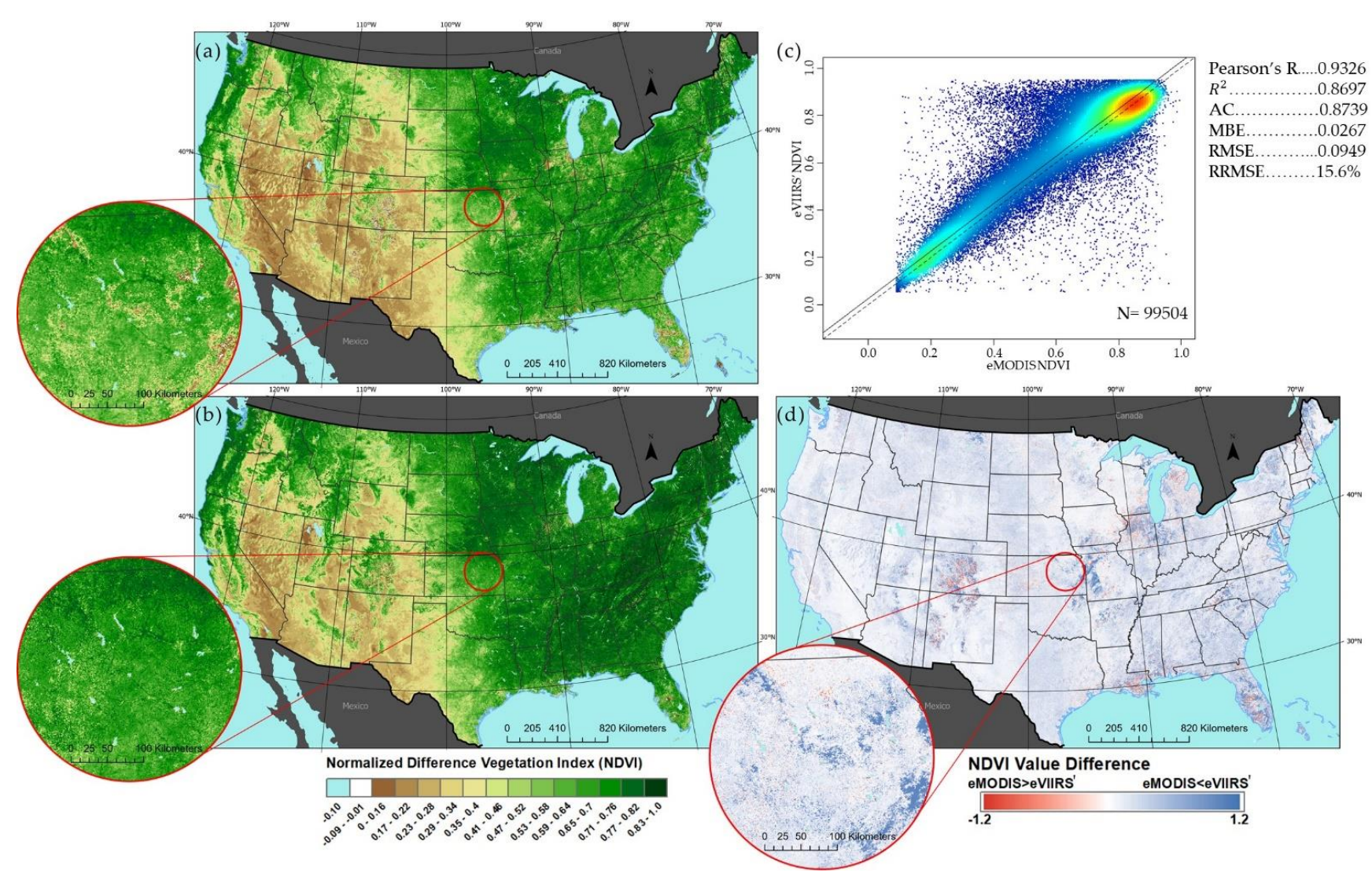

Figure 4. Expedited Moderate Resolution Imaging Spectroradiometer (eMODIS) (a) and transformed expedited Visible Infrared Imaging Radiometer Suite (eVIIRS') (b) Normalized Difference Vegetation Index (NDVI) comparison for Week 32, 2020, at 1-km resolution. (c) Statistical comparison between eVIIRS' and eMODIS for Week 32, 2020, which is one composite from the 2020 1-km column in Table 1. Point density increases from low (blue) to moderate (green) to high (red), the geometric mean regression (solid line) and the 1-to-1 line (dashed line). (d) Differences between each pixel whether eMODIS NDVI is greater than eVIIRS' NDVI (red) or eVIIRS' is greater than eMODIS (blue). 


\subsection{Vegetaion Anomaly Results}

After evaluating eVIIRS' 1-km results, the eVIIRS' NDVI 1-km inputs for four weeks of CONUS VegDRI products were tested from July 20 through August 9, 2020. With a bias toward higher eVIIRS' NDVI, we would have expected a negative bias (i.e. less drought than eMODIS) in the VegDRI products, but the bias was near zero with MBE of -0.122 . Correlations are moderately strong between eVIIRS' and eMODIS VegDRI products (Table 2). Statistically, the values have a positive correlation and modestly robust, but near 1-to-1 relation (Figure 5) with all four weeks above 0.42 (Table 2).

Table 2. Transformed expedited Visible Infrared Imaging Radiometer Suite (eVIIRS') Vegetation Drought Response Index (VegDRI) and expedited Moderate Resolution Imaging Spectroradiometer (eMODIS) VegDRI comparison statistics.

\begin{tabular}{cccccc}
\hline eVIIRS' vs. eMODIS VegDRI & Week 29 & Week 30 & Week 31 & Week 32 $^{\mathbf{1}}$ & Weeks 29-32 \\
\hline Pearson's R & 0.6522 & 0.6492 & 0.6612 & 0.6857 & 0.6631 \\
$\boldsymbol{R}^{\mathbf{2}}$ & 0.4254 & 0.4214 & 0.4371 & 0.4702 & 0.4397 \\
AC & 0.1389 & 0.1318 & 0.1703 & 0.2455 & 0.1752 \\
MBE/Accuracy & -0.0501 & -0.0794 & -0.1369 & -0.2238 & -0.1223 \\
RMSE/Uncertainty & 22.7448 & 22.9173 & 23.2202 & 23.0702 & 22.9742 \\
RRMSE (\%) & 18.1620 & 18.1265 & 18.2916 & 18.4921 & 18.2676 \\
\hline
\end{tabular}

${ }^{1}$ Week 32 is illustrated in Figure $5 c$.
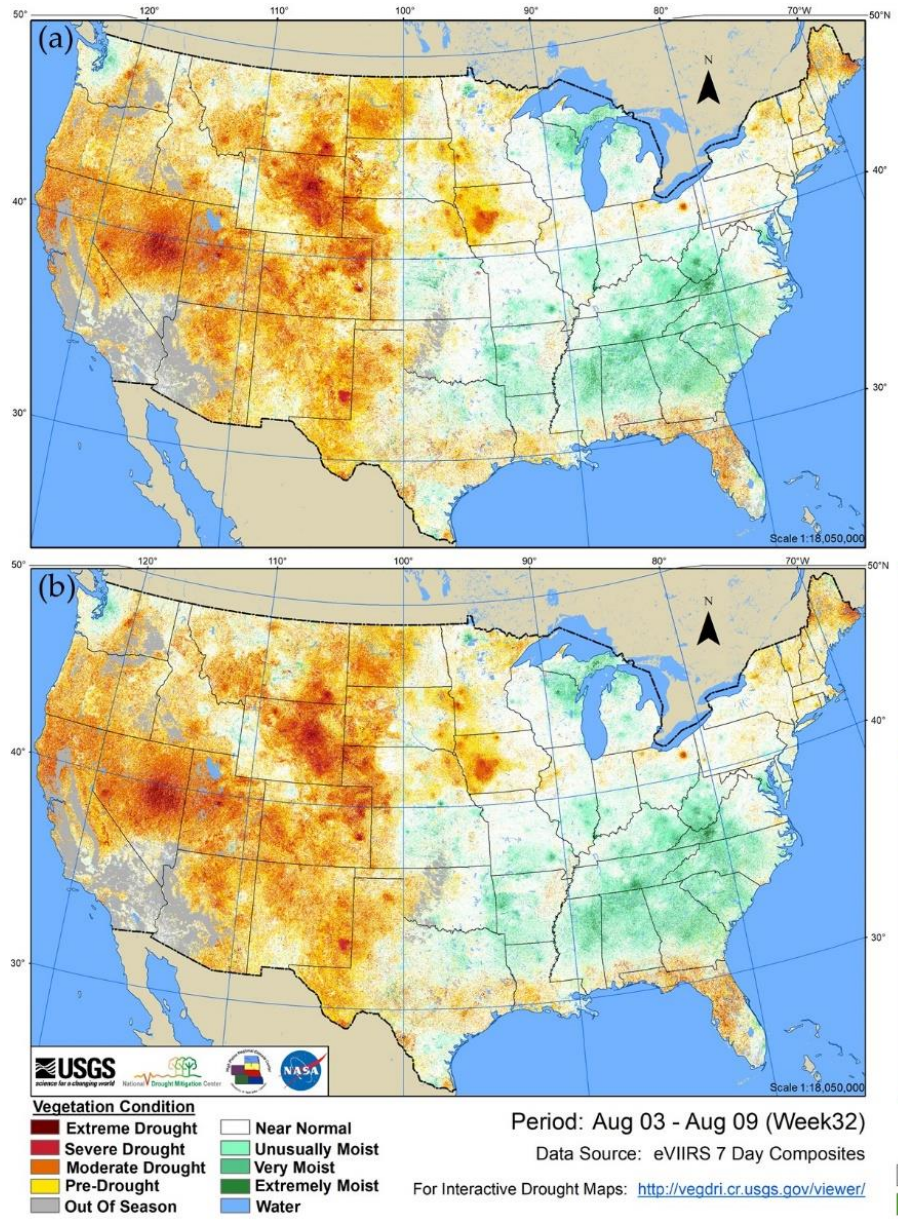

(c)
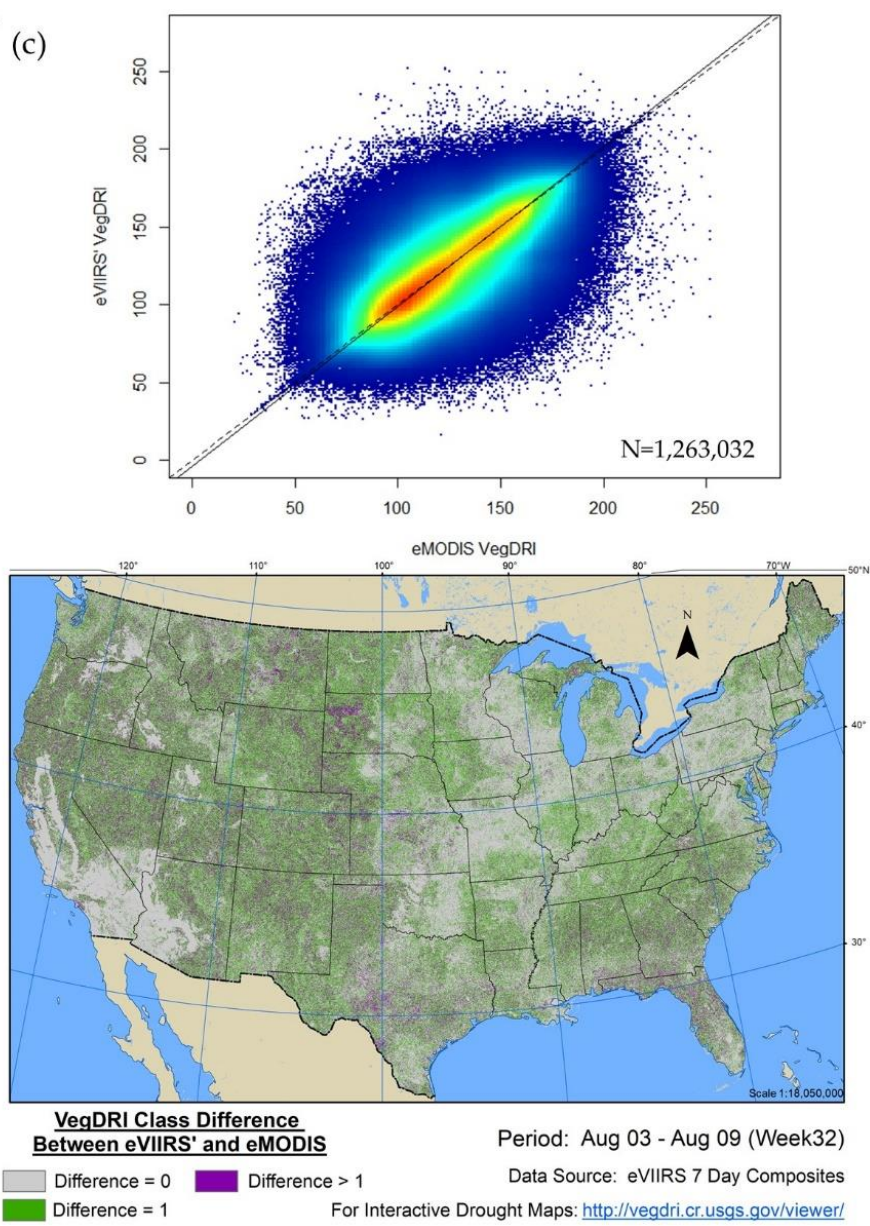

Figure 5. Comparison of Vegetation Drought Response Index (VegDRI) results from expedited Moderate Resolution Imaging Spectroradiometer (eMODIS) (a) and transformed expedited Visible Infrared Imaging Radiometer Suite (eVIIRS') (b) for week 32, 2020 (August 3, 2020 to August 9, 2020). (c) Relation between eMODIS and eVIIRS' VegDRI values, associated statistics are presented in Table 2, week 32 column. Point density increases from low (blue) to moderate (green) to high (red), the geometric mean regression (solid line) and the 1-to-1 line (dashed line). (d) VegDRI classification differences pixel by pixel. 
A visual comparison of eVIIRS' VegDRI product from week 32 (Figure 5) shows a comparable product to eMODIS VegDRI. Because VegDRI has continuous values, a bias near zero creates a linear relation near the 1-to-1 line. Clearly eVIIRS' drought hotspots geographically match those detected in the eMODIS VegDRI. An example is illustrated at the border of South Dakota and Minnesota where eMODIS VegDRI identified a small area of moderate to severe drought and the same location is also identified in eVIIRS' VegDRI (Figure $5 \mathrm{a}, \mathrm{b}$ ). The same hotspot parallelism is also noticed with the moist vegetation condition. An example is illustrated near the Alabama and Tennessee border where eMODIS VegDRI identified a small area of Extremely Moist to Very Moist, and the same location is identified in eVIIRS' VegDRI (Figure 5a,b).

The starker spatial differences that occur in eVIIRS' VegDRI products are most likely the cause of the weak correlation between the two products. Drought severity classes are predominately the same or within one class in the eVIIRS' and eMODIS VegDRI products (Figure 5d). Analyzing these products in Figure 5, the spatial distribution of the drought severity classification patterns is visually very similar between the two VegDRI products. The four weekly VegDRI products based on a pixel-level drought class comparison percentage between eVIIRS' VegDRI and eMODIS VegDRI within eVIIRS' VegDRI classes are summarized in Figure 6 . Over the CONUS, $54 \%$ of the $1-\mathrm{km}$ pixels had zero classification difference, $33 \%$ of the pixels had a one-class difference (e.g., moderate vs. severe drought) and only $13 \%$ of the pixels had a two or more class difference. Most drought class differences occur within eVIIRS' VegDRI midrange of the spectrum (Predrought to Unusually Moist categories).

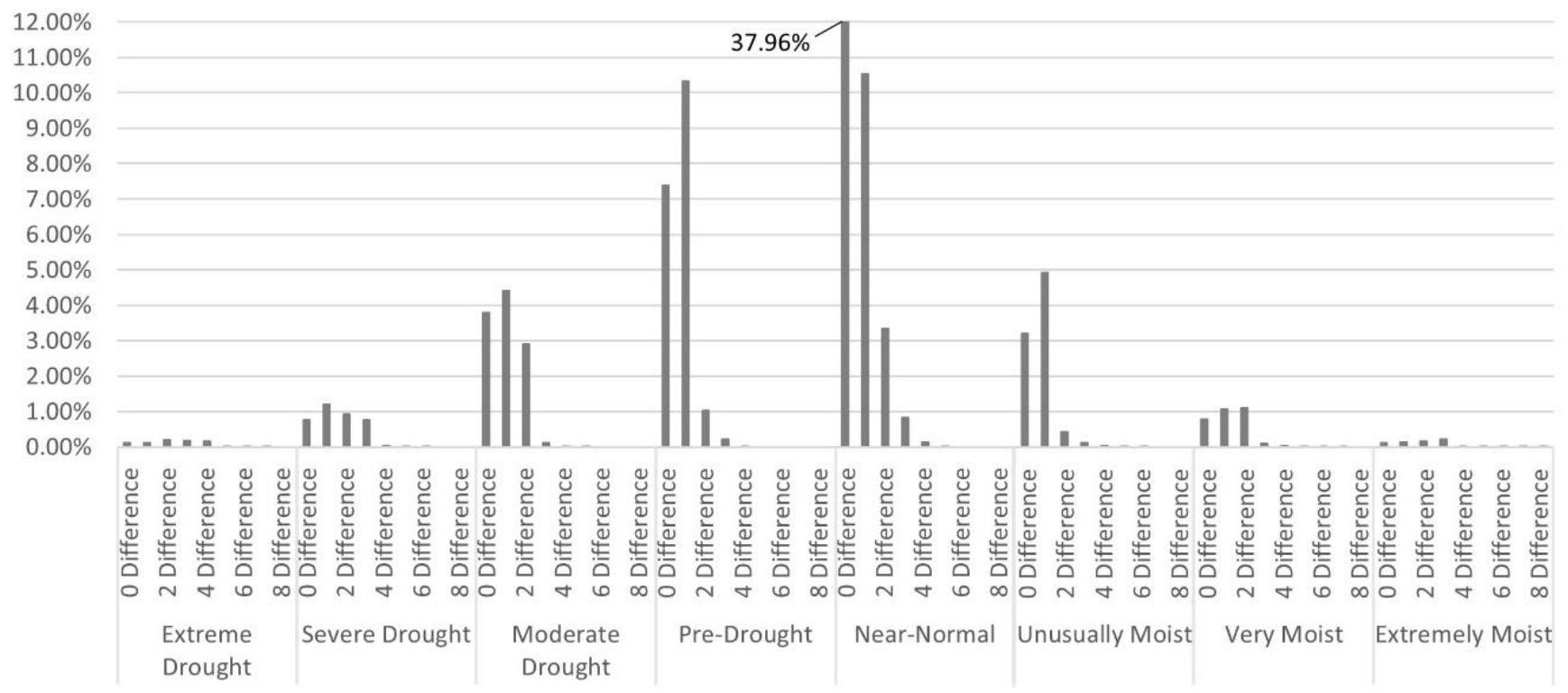

Figure 6. Total pixel classification difference between transformed expedited Visible Infrared Imaging Radiometer Suite (eVIIRS') and expedited Moderate Resolution Imaging Spectroradiometer (eMODIS) Vegetation Drought Response Index (VegDRI). For example, 37.96\% of pixels were classified by eVIIRS' as "near-normal" and were classified as the same by eMODIS, and $10.53 \%$ of the pixels called "near-normal by eVIIRS' were within 1 class in eMODIS. The percentage is based on all pixels not including changes in the Out-of-Season or water classification for all four weeks $(29,131,856$ pixels).

\section{Discussion}

\subsection{NDVI Comparison}

We created a simplistic transformation model to maintain data continuity following mission end of the Aqua MODIS platform. Data continuity is needed to support applications such as drought monitoring, where a sustained historical time-series may often require inter-sensor NDVI data. This transformation can be used by other MODIS and eMODIS users to transition from MODIS to VIIRS NDVI data for their own applications. 
These transformations allow historical longevity of NDVI data, which lengthens historical data for statistical input utilized in anomaly models. These transformations are important because transitioning from one satellite platform to another can lead to gaps in operational products like VegDRI when a sensor's life cycle ends. The Suomi-NPP VIIRS sensor helps to extend NDVI's continuous data in support for the next VIIRS missions. The longevity of VIIRS sensor products will continue to be produced with four NASA-NOAA Joint Polar Satellite System (JPSS) missions continuing through 2031 [36]. Therefore, in the transition from one satellite sensor to another, it is important to calculate comparable inter-sensor NDVI datasets to continue the historical record and provide a historically consistent, long-term NDVI dataset used for many types of environmental monitoring.

The results from this study demonstrated the use of eVIIRS' NDVI in a vegetation anomaly model (VegDRI). The eVIIRS and eMODIS NDVI composites showed a high correlation and AC using the GMR transformation equation. The errors approached zero after applying the GMR transformation. The consistent statistics throughout the three years gives us confidence to utilize these eVIIRS products in other applications. Using the lumped method (NDVI-to-NDVI) to transform eVIIRS NDVI provided a direct approach to transitioning drought models from eMODIS NDVI to eVIIRS' NDVI.

We determined that filtering out low NDVI values provides a more robust GMR transformation. Using the GMR transformation method allows a more relatable approach for changing eVIIRS NDVI to eVIIRS' NDVI, because untransformed eVIIRS yearly NDVI values have a linear relation and using a quadratic regression may manipulate the values off the 1-to-1 line more than using the linear GMR. The GMR transformation also provides an inverse adjustment that changes eMODIS values to eVIIRS-like NDVI with a simple algebraic coefficient calculation [30]. We used 2016-2018 NDVI data to test this robustness with the 2020 data, which gave us a year and a half gap from the last data received from MODIS (2018, our hypothetical situation). This transformation is useful for when MODIS approaches its end of life and models need to continue producing data, but do not have the capabilities of switching to VIIRS.

Some uncertainties come from the native resolution of the two surface reflectance datasets, which in eVIIRS NDVI is 50\% larger than eMODIS NDVI. The spatial resolution difference causes the pixel heterogeneity to vary between sensor footprints, meaning that pixel values from one sensor will differ many times from the pixel values of the other sensor. To best prevent highly heterogenous pixels, we narrowed our GMR pixel selection by masking water and poor-quality pixels throughout CONUS. To achieve a similar reflectance with each pixel, we ensured that the pixels used in our GMR transformation development were acquired on the same day, similar to Skakun et al. [20]. However, bias was still present for 2020 eVIIRS NDVI. A potential future solution to this problem would be selecting a larger sample of years that would consist of a variety of vegetation conditions and NDVI values, yielding a broadened GMR transformation.

A limitation that may affect our NDVI transformation was not applying a bidirectional reflectance distribution function (BRDF) on surface reflectance. The BRDF was not considered in our study because the transformation algorithm was created using the existing national-level eMODIS NDVI, which was not BRDF-corrected. Our approach for a non-BRDF corrected surface reflectance was similar to that of Skakun et al. [20], who did not apply a BRDF correction on their 500 -m products. This approach worked well with our composites from source daily VIIRS and MODIS granules from LANCE that are delivered approximately three hours after overpass, and supports users that require expedited data. Another limitation includes the rigid terrain that may influence NDVI. Matsushita et al. [37] studied the topographic effects on vegetation indices (Enhanced Vegetation Index [EVI] and NDVI) and found some topographic influence on these indices. With further investigation, Matsushita et al. [37] found indices that include variables without band ratioing (EVI) need to remove the topographic effect, whereas band ratioing indices (NDVI) reduces the topographic effect and can be ignored [37]. 
Another factor that could affect the results was MODIS degradation. With its end of life approaching, degradation may explain the larger bias in 2020 expedited composites compared to 2016-2018 NDVI composites. For a higher correlation in future work, we could use the smoothed NDVI values to create a GMR transformation algorithm. Brown et al. [6] found the smoothed NDVI results had a higher $R^{2}$ correlation than the unsmoothed NDVI values used in this study.

\subsection{VegDRI Comparison}

The GMR transformation, calculated from 2016-2018 MODIS-VIIRS data overlap period will be applied to eVIIRS to provide a historically consistent NDVI dataset that can be used in operational VegDRI production. This study demonstrated that eVIIRS' NDVI data can produce a near-identical VegDRI model output to that produced from the eMODIS NDVI. The current VegDRI model and products are produced using Aqua eMODIS NDVI as training data. With the Aqua MODIS platform lifespan ending soon, the GMR transformation is in place for continuity of VegDRI products.

The results of introducing eVIIRS' into VegDRI applications are closely comparable to their eMODIS-based counterparts. With the GMR transformation applied during the VegDRI process, eVIIRS' NDVI values will perform satisfactorily for drought monitoring. The RRMSE values for all VegDRI products were $18 \%$, which means the eVIIRS' VegDRI product values are a good fit compared to eMODIS VegDRI. Our confidence in replacing eMODIS with eVIIRS' in VegDRI is strong because most of the classification changes occur within a one-class difference between eVIIRS' VegDRI and eMODIS VegDRI products. Drought monitoring activities using VegDRI, such as the USDM, are generally used to make decisions based on the categorical drought designation, and a one-class difference would have minimal impact compared to two or more classes of difference. We plan to continue to build eVIIRS' VegDRI products until our models are retrained using eVIIRS.

We have featured VegDRI drought monitoring as one main operational application for the newly derived eVIIRS NDVI composites. Other applications involving research and/or product development that have utilized eMODIS composites and are likely to benefit from this research on translation of eVIIRS include (but are not limited to) phenological studies [38], irrigation land use [39], wildfire fuel load modeling [40], invasive grassland vegetation dynamics [41], and Famine Early Warning System Network [42].

\section{Conclusions}

The GMR transformation algorithm allows continuity for drought monitoring models that rely on eMODIS NDVI. In August 2020, the LANCE Aqua MODIS formatting outage malfunctioned and did not produce data for an extended period, and there was a complete shutdown onboard the platform transmission. In this event, the 24-hour latency production of VegDRI used daily VIIRS data from LANCE to develop eVIIRS' NDVI for continuity. In the future, if Aqua MODIS has another outage or ends its service, this simple-to-apply GMR transformation enables continuity between eMODIS to eVIIRS expedited transitions. This transformation is useful for when Aqua MODIS approaches its end of life in 2022 [20] and models need to continue producing data but do not yet have the capability of switching to VIIRS. This study may help other users who are hesitant about switching over to VIIRS because they are unsure of how to utilize this input in their models. Our simplistic approach to transferring our model from eMODIS to eVIIRS demonstrates the ease of use of NDVI GMR transformation for model continuity and longevity.

As the USDM process continues to evolve and more data and tools become available, one key feature is the continuation of legacy products into the USDM map. With tools that have been developed to enhance drought monitoring in the United States, such as VegDRI, it is important to see that these tools continue even if changes need to be made. The datasets and tools that have the longest duration are key in the USDM process as they have a history through many wet and dry events to compare against, and losing them would be detrimental to the USDM process. Even within the limits of how long all 
satellite-based products have been around, the high-resolution attributes associated with VegDRI are important when identifying drought and drought intensity, and transitioning to another platform would ensure that VegDRI would continue to be available to the USDM process going forward. Future study is planned to include a more comprehensive study of eVIIRS across a year (a seasonal performance study) and across multiple years for a range of drought events (e.g., moderate, severe and extreme cases). We also plan to retrain the VegDRI model with eVIIRS NDVI products. We plan to compare the eVIIRS-trained VegDRI with our eMODIS and eVIIRS' VegDRI products to gain more information on our GMR transformation accuracy.

Author Contributions: Conceptualization, J.F.B., T.D.B. and S.P.B.; Methodology, T.D.B. and D.M.H.; Software, T.D.B. and K.A.E.; Validation, B.A.F., B.D.W. and T.T.; Formal Analysis, T.D.B.; Investigation, T.D.B.; Resources, T.D.B.; Data Curation, T.D.B. and K.A.E.; Writing-Original Draft Preparation, T.D.B.; Writing-Review \& Editing, T.D.B., J.F.B., S.P.B., D.M.H., B.A.F., B.D.W., T.T. and K.A.E.; Visualization, T.D.B.; Supervision, D.M.H., J.F.B. and S.P.B.; Project Administration, D.M.H., J.F.B. and S.P.B.; Funding Acquisition, J.F.B. and S.P.B. All authors have read and agreed to the published version of the manuscript.

Funding: This research was funded by the U. S. Geological Survey National Land Imaging Program.

Institutional Review Board Statement: Not applicable.

Informed Consent Statement: Not applicable.

Data Availability Statement: The data presented in this study are openly available in EarthExplorer at https: / / doi.org/10.5066/F7H41PNT, accessed on 11 February 2021 (eMODIS) and https:/ / doi. org/10.5066/P9Q3B2A7, accessed on 11 February 2021 (eVIIRS). The data presented for VegDRI are openly available at https: / /www.usgs.gov/core-science-systems/eros/droughtstress, accessed on 11 February 2021, and https:/ / doi.org/10.3133/fs20103114, accessed on 11 February 2021.

Acknowledgments: Support for T. Benedict, J. Brown, S. Boyte, K. Evenson, and D. Howard was provided by funding from the U.S. Department of the Interior, U. S. Geological Survey, National Land Imaging Program under the Core Science Systems Mission Area. The authors also wish to thank M. Rigge for his review, and the reviewers of the manuscript for their helpful suggestions. Any use of trade, firm, or product names is for descriptive purposes only and does not imply endorsement by the U.S. Government.

Conflicts of Interest: The authors declare no conflict of interest.

\section{References}

1. Brown, J.F.; Wardlow, B.D.; Tadesse, T.; Hayes, M.J.; Reed, B.C. The Vegetation Drought Response Index (VegDRI): A new integrated approach for monitoring drought stress in vegetation. GIScience Remote Sens. 2008, 45, 16-46. [CrossRef]

2. Littell, J.S.; Peterson, D.L.; Riley, K.L.; Liu, Y.; Luce, C.H. (Eds.) Fire and Drought; U.S. Department of Agriculture, Forest Service, Washington Office: Washington, DC, USA, 2016.

3. Tadesse, T.; Demisse, G.B.; Zaitchik, B.; Dinku, T. Satellite-based hybrid drought monitoring tool for prediction of vegetation condition in Eastern Africa: A case study for Ethiopia. Water Resour. Res. 2014, 50, 2176-2190. [CrossRef]

4. Svoboda, M.; LeComte, D.; Hayes, M.; Heim, R.; Gleason, K.; Angel, J.; Rippey, B.; Tinker, R.; Palecki, M.; Stooksbury, D.; et al. The drought monitor. Bull. Am. Meteorol. Soc. 2002, 83, 1181-1190. [CrossRef]

5. Fuchs, B.A. National Drought Mitigation Center; University of Nebraska-Lincoln: Lincoln, NE, USA, 2021.

6. Brown, J.F.; Howard, D.; Wylie, B.; Frieze, A.; Ji, L.; Gacke, C. Application-ready expedited MODIS data for operational land surface monitoring of vegetation condition. Remote Sens. 2015, 7, 16226-16240. [CrossRef]

7. Jenkerson, C.B.; Maiersperger, T.; Schmidt, G. eMODIS: A User-Friendly Data Source: U.S. Geological Survey Open-File Report 2010-1055; U.S. Geological Survey EROS Center: Sioux Falls, SD, USA, 2010; p. 10. [CrossRef]

8. Wylie, B.K.; Zhang, L.; Bliss, N.; Ji, L.; Tieszen, L.L.; Jolly, W.M. Integrating modelling and remote sensing to identify ecosystem performance anomalies in the boreal forest, Yukon River Basin, Alaska. Int. J. Digit. Earth 2008, 1, 196-220. [CrossRef]

9. Boyte, S.P.; Wylie, B.K.; Major, D.J. Mapping and monitoring cheatgrass dieoff in rangelands of the Northern Great Basin, USA. Rangel. Ecol. Manag. 2015, 68, 18-28. [CrossRef]

10. Rigge, M.; Wylie, B.K.; Gu, Y.; Belnap, J.; Phuyal, K.; Tieszen, L.L. Monitoring the status of forests and rangelands in the western United States using ecosystem performance anomalies. Int. J. Remote Sens. 2013, 34, 4049-4068. [CrossRef]

11. Gulácsi, A.; Kovács, F. Drought monitoring of forest vegetation using MODIS-based normalized difference drought index in Hungary. Hung. Geogr. Bull. 2018, 67, 29-42. [CrossRef] 
12. Haroon, M.A.; Zhang, J.; Yao, F. Drought monitoring and performance evaluation of MODIS-based drought severity index (DSI) over Pakistan. Nat. Hazards 2016, 84, 1349-1366. [CrossRef]

13. Hunt, E.R., Jr.; Ustin, S.L.; Riaño, D. Remote sensing of leaf, canopy, and vegetation water contents for satellite environmental data records. In Satellite-Based Applications on Climate Change; Springer: Dordrecht, The Netherlands, 2013; Volume 9789400758728, pp. 335-357.

14. Nelson, K. Fire Danger Forecast-A Comparison of Fire Potential Index Rasters Derived from AVHRR and MODIS data. Available online: https://www.usgs.gov/ecosystems/lcsp/fire-danger-forecast/a-comparison-fire-potential-index-rastersderived-avhrr-and (accessed on 2 January 2021).

15. Becker-Reshef, I.; Vermote, E.; Lindeman, M.; Justice, C. A generalized regression-based model for forecasting winter wheat yields in Kansas and Ukraine using MODIS data. Remote Sens. Environ. 2010, 114, 1312-1323. [CrossRef]

16. Johnson, D.M. A comprehensive assessment of the correlations between field crop yields and commonly used MODIS products. Int. J. Appl. Earth Obs. Geoinf. 2016, 52, 65-81. [CrossRef]

17. Wang, D.; Morton, D.; Masek, J.; Wu, A.; Nagol, J.; Xiong, X.; Levy, R.; Vermote, E.; Wolfe, R. Impact of sensor degradation on the MODIS NDVI time series. Remote Sens. Environ. 2012, 119, 55-61. [CrossRef]

18. Vermote, E.; Franch, B.; Claverie, M. VIIRS/NPP Surface Reflectance 8-Day L3 Global 500 m SIN Grid V001 [Dataset]. Available online: https://lpdaac.usgs.gov/products/vnp09h1v001/\#using (accessed on 30 November 2020).

19. Roger, J.C.; Vermote, E.F.; Devadiga, S.; Ray, J.P. Suomi-NPP VIIRS Surface Reflectance User's Guide. Available online: https: / / viirsland.gsfc.nasa.gov/PDF/VIIRS_Surf_Refl_UserGuide_v1.3.pdf (accessed on 23 November 2020).

20. Skakun, S.; Justice, C.O.; Vermote, E.; Roger, J.C. Transitioning from MODIS to VIIRS: An analysis of inter-consistency of NDVI data sets for agricultural monitoring. Int. J. Remote Sens. 2018, 39, 971-992. [CrossRef]

21. Justice, C.O.; Román, M.O.; Csiszar, I.; Vermote, E.F.; Wolfe, R.E.; Hook, S.J.; Friedl, M.; Wang, Z.; Schaaf, C.B.; Miura, T.; et al. Land and cryosphere products from Suomi NPP VIIRS: Overview and status. J. Geophys. Res. Atmos. 2013, 118, 9753-9765. [CrossRef] [PubMed]

22. Zhang, X.; Liu, L.; Liu, Y.; Jayavelu, S.; Wang, J.; Moon, M.; Henebry, G.M.; Friedl, M.A.; Schaaf, C.B. Generation and evaluation of the VIIRS land surface phenology product. Remote Sens. Environ. 2018, 216, 212-229. [CrossRef]

23. Kogan, F.; Goldberg, M.; Schott, T.; Guo, W. Suomi NPP/VIIRS: Improving drought watch, crop loss prediction, and food security. Int. J. Remote Sens. 2015, 36, 5373-5383. [CrossRef]

24. Ji, L.; Gallo, K.; Eidenshink, J.C.; Dwyer, J. Agreement evaluation of AVHRR and MODIS 16-day composite NDVI data sets. Int. J. Remote Sens. 2008, 29, 4839-4861. [CrossRef]

25. Miura, T.; Turner, J.P.; Huete, A.R. Spectral Compatibility of the NDVI Across VIIRS, MODIS, and AVHRR: An Analysis of Atmospheric Effects Using EO-1 Hyperion. IEEE Trans. Geosci. Remote Sens. 2013, 51, 1349-1359. [CrossRef]

26. Miura, T.; Muratsuchi, J.; Vargas, M. Assessment of cross-sensor vegetation index compatibility between VIIRS and MODIS using near-coincident observations. J. Appl. Remote Sens. 2018, 12. [CrossRef]

27. Fan, X.; Liu, Y. A comparison of NDVI intercalibration methods. Int. J. Remote Sens. 2017, 38, 5273-5290. [CrossRef]

28. Ricker, W.E. Computation and use of central lines. Can. J. Zool. 1984, 62, 1897-1905. [CrossRef]

29. Laws, E.A.; Archie, J.W. Appropriate use of regression analysis in marine biology. Mar. Biol. 1981, 65, 13-16. [CrossRef]

30. Ji, L.; Gallo, K. An agreement coefficient for image comparison. Photogramm. Eng. Remote Sens. 2006, 72, 823-833. [CrossRef]

31. Ji, L.; Wylie, B.; Ramachandran, B.; Jenkerson, C. A comparative analysis of three different MODIS NDVI datasets for Alaska and adjacent Canada. Can. J. Remote Sens. 2010, 36, S149-S167. [CrossRef]

32. Rouse, J.W., Jr.; Haas, R.H.; Schell, J.A.; Deering, D.W. Monitoring Vegetation Systems in the Great Plains with ERTS; NASA Special Publication: Washington, DC, USA, 1974; Volume 351.

33. Jia, G.J.; Epstein, H.E.; Walker, D.A. Spatial heterogeneity of tundra vegetation response to recent temperature changes. Glob. Chang. Biol. 2006, 12, 42-55. [CrossRef]

34. Despotovic, M.; Nedic, V.; Despotovic, D.; Cvetanovic, S. Evaluation of empirical models for predicting monthly mean horizontal diffuse solar radiation. Renew. Sustain. Energy Rev. 2016, 56, 246-260. [CrossRef]

35. Li, M.F.; Tang, X.P.; Wu, W.; Liu, H.B. General models for estimating daily global solar radiation for different solar radiation zones in mainland China. Energy Convers. Manag. 2013, 70, 139-148. [CrossRef]

36. Wolfe, R. Visible Infrared Imaging Radiometer Suite (VIIRS). Available online: https://ladsweb.modaps.eosdis.nasa.gov/ missions-and-measurements/viirs / (accessed on 29 January 2021).

37. Matsushita, B.; Yang, W.; Chen, J.; Onda, Y.; Qiu, G. Sensitivity of the enhanced vegetation index (EVI) and normalized difference vegetation index (NDVI) to topographic effects: A case study in high-density cypress forest. Sensors 2007, 7, 2636-2651. [CrossRef] [PubMed]

38. Brown, J.F.; Ji, L.; Gallant, A.; Kauffman, M. Exploring relationships of spring green-up to moisture and temperature across Wyoming, U.S.A. Int. J. Remote Sens. 2019, 40, 956-984. [CrossRef]

39. Brown, J.F.; Pervez, M.S. Merging remote sensing data and national agricultural statistics to model change in irrigated agriculture. Agric. Syst. 2014, 127, 28-40. [CrossRef]

40. Li, Z.; Shi, H.; Vogelmann, J.E.; Hawbaker, T.J.; Peterson, B. Assessment of fire fuel load dynamics in shrubland ecosystems in the western United States using MODIS products. Remote Sens. 2020, 12, 1911. [CrossRef] 
41. Boyte, S.P.; Wylie, B.K.; Major, D.J. Cheatgrass percent cover change: Comparing recent estimates to climate change-Driven predictions in the Northern Great Basin. Rangel. Ecol. Manag. 2016, 69, 265-279. [CrossRef]

42. Funk, C.; Shukla, S.; Thiaw, W.M.; Rowland, J.; Hoell, A.; McNally, A.; Husak, G.; Novella, N.; Budde, M.; Peters-Lidard, C.; et al. Recognizing the famine early warning systems network over 30 years of drought early warning science advances and partnerships promoting global food security. Bull. Am. Meteorol. Soc. 2019, 100, 1011-1027. [CrossRef] 